\title{
Cataract surgery following KAMRA presbyopic implant
}

This article was published in the following Dove Press journal:

Clinical Ophthalmology

19 September 2013

Number of times this article has been viewed

\author{
Tien-En Tan ${ }^{1,2}$ \\ Jodhbir S Mehta ${ }^{2-4}$ \\ 'Yong Loo Lin School of Medicine, \\ National University of Singapore, \\ Singapore; ${ }^{2}$ Singapore National \\ Eye Centre, Singapore; ${ }^{3}$ Singapore \\ Eye Research Institute, Singapore; \\ ${ }^{4}$ Department of Clinical Sciences, \\ Duke-NUS Graduate Medical School, \\ Singapore
}

\begin{abstract}
Intrastromal corneal inlays are an emerging treatment for presbyopic patients. The KAMRA $^{\mathrm{TM}}$ small aperture inlay was the first such inlay to receive Conformité Européenne (CE) marking in 2005. It has been shown to improve uncorrected near and intermediate visual acuity without adversely affecting uncorrected distance visual acuity. Due to the age of presbyopic patients, they may eventually develop cataracts. In two such cases, we found that cataract surgery with the KAMRA implant left in place was not technically more difficult, and that the surgical procedure could be improved by additional ocular rotations to improve visualization. Biometry readings were reliable, and it appeared that the SRK/T formula was accurate for calculation of intraocular lens power. Cataract surgery with the KAMRA implant left in situ is a viable option for patients.
\end{abstract}

Keywords: cataract surgery, KAMRA, corneal inlay, AcuTarget, presbyopia

\section{Introduction}

Presbyopia affects an estimated one billion people worldwide. ${ }^{1}$ Current surgical treatment options for presbyopia depend on the presence of a cataract at initial assessment. If present, a cataract extraction with the implantation of a multifocal or accommodative intraocular lens implantation may be chosen., ${ }^{2,3}$ If a clear lens is present, a non-lens-based treatment, eg, presbyopic laser-assisted in situ keratomileusis (LASIK), monovision with a contact lens or LASIK, conductive keratoplasty or femtosecond laser intrastromal presbyopia treatment (INTRACOR ${ }^{\mathrm{TM}}$; Technolas Perfect Vision GmbH, Munich, Germany) may be the preferred choice.

One emerging non-lens-based treatment modality for presbyopia is the insertion of intrastromal corneal inlays that work by a variety of different mechanisms. The Vue ${ }^{\text {TM }}$ (ReVision Optics, Lake Forest, CA, USA) inlay consists of a space-occupying lenticule that changes corneal curvature, creating a hyperprolate cornea for both near and distance vision. ${ }^{4}$ The Flexivue Microlens ${ }^{\mathrm{TM}}$ (Presbia, Amsterdam, Netherlands) inlay is itself a bifocal inlay, with a plano central zone for distance vision and a peripheral annulus with refractive add power for near vision. ${ }^{5}$ Both the Vue+ and Flexivue Microlens inlays have received Conformité Européenne (CE) marking, but are not yet US Food and Drug Administration (FDA)-approved. The KAMRA ${ }^{\mathrm{TM}}$ small aperture inlay (AcuFocus, Irvine, CA, USA), previously known as the ACI $7000^{\mathrm{TM}}$, has a $3.8 \mathrm{~mm}$ outer diameter and an inner $1.6 \mathrm{~mm}$ central aperture that selects for central light rays and creates a pinhole effect, thus increasing the depth of focus. This is inserted in the nondominant eye, and has been shown to improve uncorrected near visual acuity (UNVA), without affecting uncorrected distance visual acuity
Correspondence: Jodhbir S Mehta

Singapore National Eye Centre, II Third Hospital Avenue, Singapore 16875 I

Tel +65 62277255

Fax +6563231903

Email jodmehta@gmail.com 
(UDVA). ${ }^{6}$ The KAMRA inlay was the first corneal inlay for presbyopia to receive CE marking in 2005, and is currently pending approval from the FDA for use in the USA outside of clinical trials.

Presbyopia typically affects patients from about 40 years of age, and phakic patients who undergo corneal inlay implantation may subsequently develop cataracts as they grow older. As corneal inlay implantation for presbyopia is relatively new, there are not many patients who have yet undergone cataract surgery after corneal inlay implantation. Potential concerns with this procedure include technical difficulty performing cataract surgery with the corneal inlay in place, accuracy of biometry readings, and visual outcome after cataract surgery.

This paper presents the experiences and results of two patients who underwent phacoemulsification and intraocular lens implantation for cataracts that developed after implantation of the KAMRA corneal inlay for presbyopia.

\section{Cases}

The two patients in this case series, aged 53 and 62 years of age, were first seen in January 2010 and May 2007, respectively, at the Singapore National Eye Centre, Singapore, requesting for correction of presbyopia without the use of corrective lenses. Both patients had good UDVA, but poor UNVA (Table 1). Slit-lamp examination of the anterior and posterior segments revealed no significant abnormalities, and both patients had lenses graded as NC1 according to the Lens Opacities Classification System III (LOCS III) ${ }^{7}$ in their nondominant left eyes. Neither patient had had previous ocular surgery or other ocular history of note. Various surgical options were presented to the patients, and each opted for implantation of the KAMRA corneal inlay. One patient underwent implantation of the KAMRA corneal inlay with a microkeratome-created lamellar flap and the other had implantation via a femtosecond laser-created lamellar flap. There were no surgical or early postoperative complications. Table 1 summarizes the visual outcomes of the patients 1 month after implantation.

\section{Case I}

Case 1, a 53-year-old Chinese male, underwent implantation of the KAMRA corneal inlay in the nondominant left eye on January 6, 2010. A 7.80 mm-diameter lamellar flap was created at a depth of 190 microns with a VisuMax ${ }^{\text {TM }}$ femtosecond laser (Carl Zeiss Meditec, Jena, Germany). The corneal inlay was implanted without complication. The patient's pre- and 1-month postoperative visual acuity results can be found in Table 1. A slit-lamp photograph of the KAMRA corneal inlay in place is shown in Figure 1.

Twelve months after implantation, even though reading well, the patient noted ghosting and slight monocular diplopia in the left eye. This was felt to be due to the position of the KAMRA inlay. The patient underwent surgical repositioning of the implant, resulting in resolution of his symptoms. Figure 2 shows AcuTarget ${ }^{\mathrm{TM}}$ (AcuFocus) photographs of the KAMRA implant positioning before and after surgical repositioning.

Seven months after repositioning of the implant, the patient had an UNVA of J10 and was noted to have developed cataract of grade NC3P3 (LOCS III) in the left eye. Various options were discussed with the patient, including cataract surgery with the implant in place, removal of the implant followed by cataract surgery and subsequent re-implantation, and implant removal followed by cataract surgery with a multifocal or accommodative intraocular lens implant. Centration of the KAMRA implant was confirmed with AcuTarget photographs (Figure 2). Due to the excellent centration (inlay vs Purkinje: $-95 \mu \mathrm{m} x,-27 \mu \mathrm{m} y)$, the patient opted for cataract surgery, leaving the KAMRA implant in place. Biometry

Table I Distance and near visual acuity before KAMRA implantation, I month after KAMRA implantation, before cataract surgery, and I month after cataract surgery, for cases I and 2

\begin{tabular}{|c|c|c|c|c|c|}
\hline Measurement & Case & $\begin{array}{l}\text { Before KAMRA } \\
\text { implantation }\end{array}$ & $\begin{array}{l}\text { I month after KAMRA } \\
\text { implantation }\end{array}$ & $\begin{array}{l}\text { Before cataract } \\
\text { surgery }\end{array}$ & $\begin{array}{l}\text { I month after } \\
\text { cataract surgery }\end{array}$ \\
\hline \multirow[t]{2}{*}{ UDVA } & 1 & $20 / 30$ & $20 / 40$ & $20 / 50$ & $20 / 40$ \\
\hline & 2 & $20 / 12.5^{-1}$ & $20 / 25^{+1}$ & $20 / 50^{+2}$ & $20 / 20$ \\
\hline \multirow[t]{2}{*}{ CDVA } & 1 & $20 / 20$ & $20 / 25$ & $20 / 30$ & $20 / 30$ \\
\hline & 2 & $20 / 16$ & $20 / 20^{+1}$ & $20 / 30$ & $20 / 20$ \\
\hline \multirow[t]{2}{*}{ UNVA } & I & $\mathrm{j} 3$ & $\mathrm{~J} 3$ & J10 & $12^{\mathrm{a}}$ \\
\hline & 2 & J6 & $\mathrm{J} 2$ & $\mathrm{j} 2$ & $\mathrm{~J} 2$ \\
\hline \multirow[t]{2}{*}{ Manifest refraction (D) } & 1 & Plano/-0.75 × 095 & $-0.50 /-0.50 \times 070$ & $-0.50 /-0.50 \times 090$ & Plano/- $0.75 \times 025$ \\
\hline & 2 & $+0.25 /$ plano & $+0.50 /$ plano & $-0.50 /-0.75 \times 175$ & Plano/-0.75 × 175 \\
\hline
\end{tabular}

Notes: aUNVA result after Nd:YAG laser capsulotomy for posterior capsular opacification, 6 weeks after cataract surgery. KAMRA: AcuFocus, Irvine, CA, USA. Abbreviations: UDVA, uncorrected distance visual acuity; CDVA, corrected distance visual acuity; UNVA, uncorrected near visual acuity. 


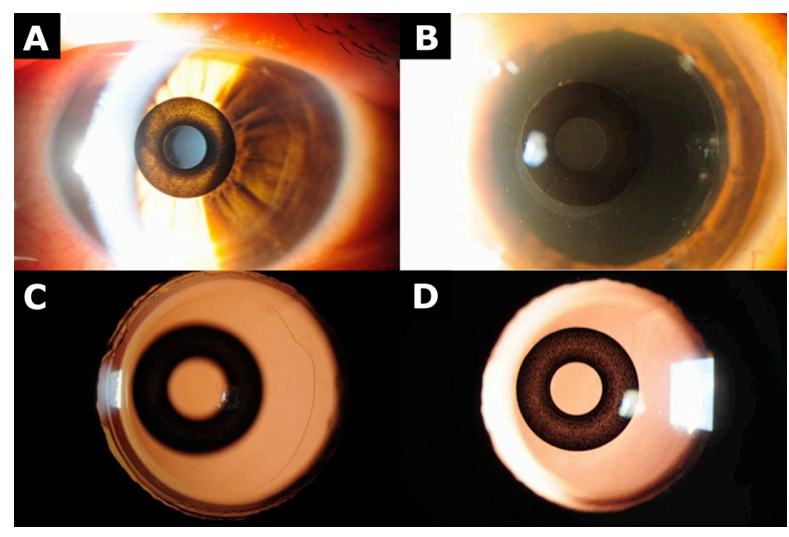

Figure I Slit-lamp photographs from case I.

Notes: (A) KAMRA implant following initial implantation. (B) KAMRA implant following recentration. (C) Retroillumination photograph to illustrate the circularity of the capsulorhexis. (D) KAMRA implant I month after cataract surgery. KAMRA: AcuFocus, Irvine, CA, USA.

parameters are summarized in Table 2. Corneal topography remained stable after implantation of the KAMRA inlay and before cataract surgery (Figure 3).

The patient underwent uncomplicated phacoemulsification and intraocular lens implantation of the left eye under local anesthesia. A $2.60 \mathrm{~mm}$ temporal clear corneal incision was made, and a $+22.0 \mathrm{D}$ monofocal Tecnis ${ }^{\circledR}$ ZCB00 intraocular lens (Abbott Medical Optics, Santa Ana, CA, USA) was implanted. No modifications were made to the surgical procedure, and the surgeon reported no difference in the ease of surgery with the KAMRA implant in place, apart from a few extra ocular rotations during capsulorhexis and phacoemulsification to improve visualization. There were no intraoperative complications, and surgical time was 15 minutes. Slit-lamp photographs taken after cataract surgery can be seen in Figure 1. One month after cataract surgery, posterior capsular opacification was noted in the left eye, and the patient underwent Nd:YAG laser capsulotomy 6 weeks after cataract surgery (Figure 1). The objective visual outcome is reported in Table 1. The subjective outcome was also good. The patient reported good near, intermediate, and

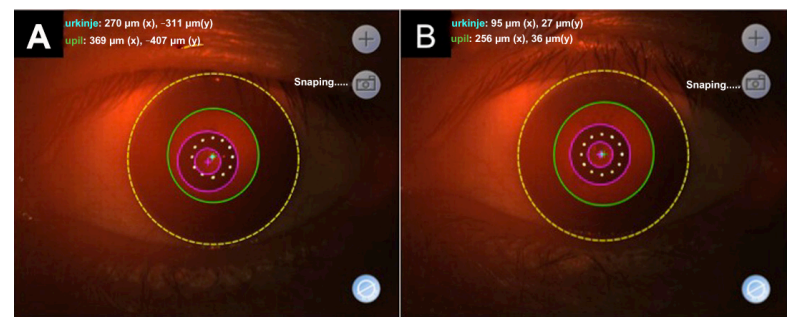

Figure 2 AcuTarget photographs of KAMRA implant before and 7 months after repositioning, for case 1 .

Notes: (A) Before repositioning of KAMRA implant. (B) 7 months after repositioning of KAMRA implant. KAMRA, AcuTarget: AcuFocus, Irvine, CA, USA. distance vision without the use of spectacles, and remains spectacle-independent.

\section{Case 2}

Case 2, a 62-year-old Chinese male, underwent implantation of the KAMRA corneal inlay in the nondominant left eye on July 4, 2007. A 9.00 mm-diameter lamellar flap was created at a depth of 151 microns with a SCHWIND microkeratome (SCHWIND, Kleinostheim, Germany). The corneal inlay was implanted without complication. The patient's pre- and 1 -month postoperative visual acuity results can be found in Table 1.

Four years after KAMRA implantation, cataract of grade NC2 (LOCS III) was noted in the implanted left eye. Nevertheless, vision in this eye remained good; UDVA was 20/20 ${ }^{-1}$ and UNVA was J2. However, 6 years after KAMRA implantation, the patient felt that his distance vision in the left eye had deteriorated significantly (Table 1) and, on assessment, cataract of grade NC4 (LOCS III) was noted. AcuTarget photographs confirmed that the implant was well centered (inlay vs Purkinje: $-146 \mu \mathrm{m} \mathrm{x},-78 \mu \mathrm{m}$ y). Various treatment options were presented to the patient, who opted for cataract surgery, leaving the KAMRA implant in place. Biometry parameters used are listed in Table 2.

The patient underwent phacoemulsification and intraocular lens implantation of the left eye under local anesthesia. A $2.60 \mathrm{~mm}$ temporal clear corneal incision was made, and $\mathrm{a}+20.0$ D monofocal Tecnis ZCB00 intraocular lens was implanted. No modifications were made to the surgical technique, and the surgeon reported no difference in ease of the surgery with the KAMRA implant in place, except that some extra ocular rotations during capsulorhexis and phacoemulsification to optimize the surgical view were required. Surgical time was 15 minutes, and there were no intraoperative or early postoperative complications. The objective visual outcome 1 month after cataract surgery is reported in Table 1. The subjective outcome was also good. The patient reported good near, intermediate and distance vision without the use of spectacles, and remains spectacle-independent.

\section{Discussion}

Implantation of the KAMRA corneal inlay is an effective nonlens-based treatment option for presbyopia in patients with a clear lens at the time of presentation. ${ }^{6}$ However, some of these patients may eventually develop cataracts requiring surgical treatment. At this point, there are a multitude of available options, including cataract surgery with the KAMRA implant in place, implant removal followed by cataract surgery and 
Table 2 Biometry, method of biometry calculation, formula for biometry calculation, target power, and power achieved after cataract surgery, for cases $I$ and 2

\begin{tabular}{|c|c|c|c|c|c|c|c|c|c|}
\hline \multirow[t]{2}{*}{ Case } & \multicolumn{5}{|c|}{ Biometry } & \multirow{2}{*}{$\begin{array}{l}\text { Method of } \\
\text { biometry } \\
\text { calculation }\end{array}$} & \multirow{2}{*}{$\begin{array}{l}\text { Formula for } \\
\text { biometry } \\
\text { calculation }\end{array}$} & \multirow{2}{*}{$\begin{array}{l}\text { Target } \\
\text { power (D) }\end{array}$} & \multirow{2}{*}{$\begin{array}{l}\text { Power achieved } \\
\text { after cataract } \\
\text { surgery (D) }\end{array}$} \\
\hline & KI (D) & K2 (D) & $\mathrm{AL}(\mathrm{mm})$ & $\mathrm{ACD}(\mathrm{mm})$ & Cyl (D) & & & & \\
\hline I & 46.75 & 46.00 & 22.50 & 3.06 & $-0.75 \times 078$ & $\begin{array}{l}\text { Ultrasound } \\
\text { A-scan }\end{array}$ & $\mathrm{SRK} / \mathrm{T}$ & -0.33 & -0.38 \\
\hline 2 & 43.95 & 44.94 & 24.06 & 4.85 & $-0.99 \times 022$ & IOLMaster $^{\circledR}$ & $\mathrm{SRK} / \mathrm{T}$ & -0.72 & -0.38 \\
\hline
\end{tabular}

Note: KI/K2 = corneal refractive power I/2. IOLMaster ${ }^{\circledR}$ : Carl Zeiss Meditec, Jena, Germany.

Abbreviations: $A C D$, anterior chamber depth; $A L$, axial length; $C y l$, cylinder.

subsequent re-implantation, and implant removal followed by cataract surgery with implantation of a multifocal or accommodative intraocular lens. Cataract surgery with the KAMRA implant in place poses a few potential concerns, such as technical difficulty performing cataract surgery with the implant in place, the accuracy of biometry readings with various intraocular lens power formulae, and the visual outcome following cataract surgery.

Regarding the technical aspects of cataract surgery, no significant modifications to the surgical technique were required in either case, and the surgeon reported no significant difference in the ease of surgery; surgical time was 15 minutes in both cases. The only slight difference was the need for some additional ocular rotations during capsulorhexis and phacoemulsification in order to improve surgical visualization. Since both patients underwent local anesthesia, this was easily performed by asking them to voluntarily rotate the eye during the surgery. The authors feel that such rotations do not significantly increase the risk of intraoperative complications, such as radial tears or opening of the posterior capsule, as the surgical view through the $1.6 \mathrm{~mm}$ central aperture after rotation was very good and, as such, a $5 \mathrm{~mm}$ capsulorhexis and phacoemulsification were performed without difficulty. However, we acknowledge the experience of the surgeon performing the cataract operations in the patients in this series. Therefore, cataract surgery with the KAMRA implant in place was not significantly more technically difficult to perform.

The visual outcomes for both near and distance vision after cataract surgery were good. The UNVA was J2 for both patients. Corrected and unaided distance visual acuities varied from 20/20 to 20/40 (Table 1). The subjective outcome was also good for both cases. Both patients were satisfied with their near, intermediate, and distance vision and remained spectacle-independent.

The biometry readings and calculations were satisfactory and accurately predicted the achieved power (Table 2). In this series, the surgeon used only one formula, SRK/T, to calculate the power of the intraocular lenses. Since there were no prior publications on this topic, an attempt was made, retrospectively, to determine if this choice of formula was reasonable. A comparison was made between four commonly used formulae for the calculation of intraocular lens power, to see which would have most accurately predicted the achieved power after surgery. The biometry readings for both cases were used for this purpose (Table 2). In case 1, using SRK/T, a +22.0 D monofocal Tecnis ZCB00 intraocular lens was implanted, aiming for a target power of $-0.33 \mathrm{D}$. The achieved spherical equivalent was $-0.38 \mathrm{D}$, ie, a difference of $0.05 \mathrm{D}$. The same biometry data were entered into three other

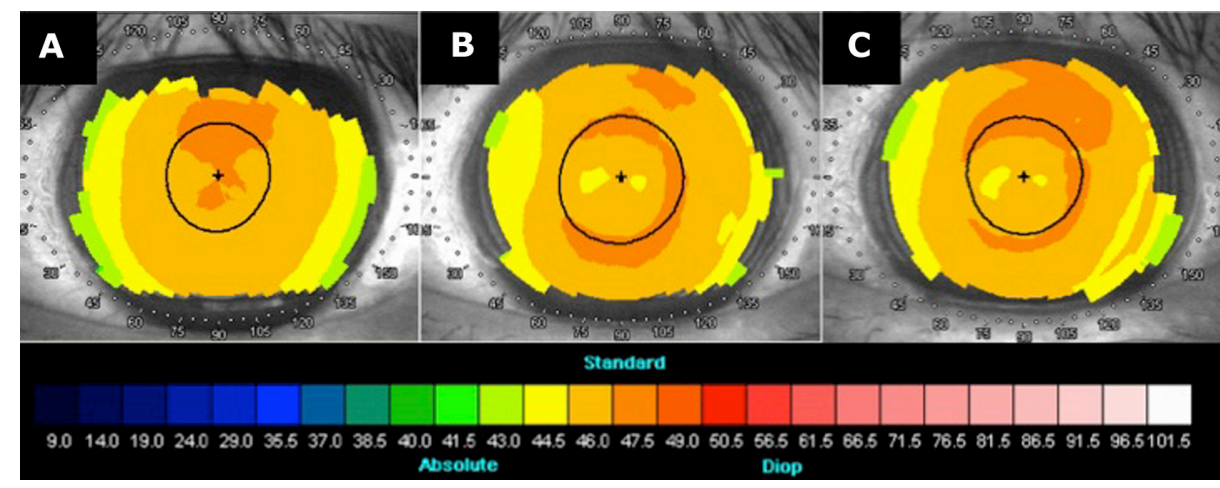

Figure 3 Corneal topography before KAMRA implantation, I year after KAMRA implantation, and before cataract surgery, for case I.

Notes: (A) Before KAMRA implantation. (B) I year after KAMRA implantation. (C) Before cataract surgery. KAMRA: AcuFocus, Irvine, CA, USA. 
commonly used formulae (Haigis, Holladay 1, and Hoffer Q), and the same $+22.0 \mathrm{D}$ Tecnis ZCB00 lens was chosen. For Haigis, the target power was $-0.76 \mathrm{D}$, with a difference of $0.38 \mathrm{D}$ from the achieved power of $-0.38 \mathrm{D}$. For Holladay 1 , the target power was $-0.51 \mathrm{D}$ (a $0.13 \mathrm{D}$ difference). Hoffer $\mathrm{Q}$ gave a target of $-0.60 \mathrm{D}$, with a difference of $0.22 \mathrm{D}$ from the achieved power. In case 1, it appears that SRK/T was the formula that most accurately predicted the achieved spherical equivalent. For case 2, using SRK/T, a +20.0 D monofocal Tecnis ZCB00 intraocular lens was implanted, aiming for a target power of $-0.72 \mathrm{D}$. The achieved spherical equivalent was $-0.38 \mathrm{D}$, giving a difference of $0.34 \mathrm{D}$. Using the same biometry parameters and the same $+20.0 \mathrm{D}$ Tecnis ZCB00 lens, Haigis gave a target of $-0.56 \mathrm{D}$ (a difference of $0.18 \mathrm{D}$ ); Holladay 1 gave a target of $-0.87 \mathrm{D}$, with a difference of $0.49 \mathrm{D}$; and Hoffer Q gave a target of $-1.00 \mathrm{D}$, with a difference of $0.62 \mathrm{D}$. In case $2, \mathrm{SRK} / \mathrm{T}$ was the second most accurate formula. Therefore, based on these retrospective calculations, SRK/T appears to be a reasonable choice of formula for choice of intraocular lens. However, this case series is too small to definitively establish the validity of SRK/T in KAMRA implant patients. Neither patient in this series underwent LASIK combined with KAMRA implantation. In such a situation, alternative formulae may be required.

Biometry readings and intraocular lens power calculations were not done prior to KAMRA implantation. However, in order to compare the biometry calculations before and after KAMRA implantation, the authors retrospectively calculated biometry for both cases before KAMRA implantation. The assumption was made that there was no change in axial length in either case. For case 1, the pre-KAMRA K readings were 47.14 and 45.99; hence, using the same $+22.0 \mathrm{D}$ lens would have given a target outcome of $-0.46 \mathrm{D}$ instead of $-0.33 \mathrm{D}$. For case 2 , the pre-KAMRA $\mathrm{K}$ readings were 44.30 and 43.50 , and so using a $+20.0 \mathrm{D}$ lens, as was done in case 2, would have given a target outcome of $-0.33 \mathrm{D}$ instead of -0.72 D. Therefore, implantation of the KAMRA inlay does not appear to have had a major effect on the biometry or intraocular lens calculations in these two patients.

\section{Conclusion}

Cataract surgery with the KAMRA implant in place is technically feasible with slight modifications to surgical technique. Visual outcomes for both near and distance vision were satisfactory. Additionally, the biometry readings were accurate, and SRK/T appears to be an accurate formula for the prediction of eventual power. However, this case series is too small for drawing definitive conclusions, and larger studies with longer follow-up will be needed to properly evaluate the safety and visual outcome of cataract surgery with the KAMRA implant in place, as well as to determine the appropriate formula for calculation of intraocular lens power. Nevertheless, cataract surgery with the KAMRA implant in place appears to be an attractive option for patients presenting with a cataract after previous KAMRA implantation for presbyopia correction.

\section{Disclosure}

The authors report no conflicts of interest in this work.

\section{References}

1. Holden BA, Fricke TR, Ho SM, et al. Global vision impairment due to uncorrected presbyopia. Arch Ophthalmol. 2008;126(12):1731-1739.

2. Agresta B, Knorz MC, Kohnen T, Donatti C, Jackson D. Distance and near visual acuity improvement after implantation of multifocal intraocular lenses in cataract patients with presbyopia: a systematic review. J Refract Surg. 2012;28(6):426-435.

3. Buznego C, Trattler WB. Presbyopia-correcting intraocular lenses. Curr Opin Ophthalmol. 2009;20(1):13-18.

4. Waring GO 4th, Klyce SD. Corneal inlays for the treatment of presbyopia. Int Ophthalmol Clin. 2011;51(2):51-62.

5. Limnopoulou AN, Bouzoukis DI, Kymionis GD, et al. Visual outcomes and safety of a refractive corneal inlay for presbyopia using femtosecond laser. J Refract Surg. 2013;29(1):12-18.

6. Yilmaz OF, Bayraktar S, Agca A, Yilmaz B, McDonald MB, van de Pol C. Intracorneal inlay for the surgical correction of presbyopia. $J$ Cataract Refract Surg. 2008;34(11):1921-1927.

7. Chylack LT, Jr., Wolfe JK, Singer DM, et al. The Lens Opacities Classification System III. The Longitudinal Study of Cataract Study Group. Arch Ophthalmol. 1993;111(6):831-836.
Clinical Ophthalmology

\section{Publish your work in this journal}

Clinical Ophthalmology is an international, peer-reviewed journal covering all subspecialties within ophthalmology. Key topics include: Optometry; Visual science; Pharmacology and drug therapy in eye diseases; Basic Sciences; Primary and Secondary eye care; Patient Safety and Quality of Care Improvements. This journal is indexed on

\section{Dovepress}

PubMed Central and CAS, and is the official journal of The Society of Clinical Ophthalmology (SCO). The manuscript management system is completely online and includes a very quick and fair peer-review system, which is all easy to use. Visit http://www.dovepress.com/ testimonials.php to read real quotes from published authors. 